\title{
Diacetylene-Containing Polymers V. Synthesis and Characterization of High Molecular Weight Diacetylene Containing Thermoplastic Polyesters: Poly(octa-3,5-diynylene succinate), Poly(octa-3,5- diynylene adipate), and Poly(octa-3,5-diynylene sebacate)
}

\author{
Sergei Fomin, Ricardo Neyra, and Takeshi Ogawa* \\ Instituto de Investigaciones en Materiales, \\ Universisad Nacional Autonoma de Mexico, \\ Apartado Postal 70-360, Coyoacan, \\ Mexico DF, 04510 Mexico
}

(Received December 9, 1993)

\begin{abstract}
New diacetylene-containing polymers: poly(octa-3,5-diynylene succinate), poly(octa-3,5-diynylene adipate, and poly(octa-3,5-diynylene sebacate) were synthesized by oxidative polycoupling of the corresponding bis-acetylenes to give high molecular weight thermoplastic film and fiber forming polymers. The polymers were thermo- and photosensitive and underwent topochemical cross-polymerization either on irradiation or heating in crystalline state to give polydiacetylene network. They can be stretched at room temperature to give strong, transparent anisotropic photosensitive materials.
\end{abstract}

KEY WORDS

Polydiacetylene / Diacetylene / Polyester / Oxidative Coupling /

Polydiacetylenes have potential application in nonlinear optics because of their conjugated en-yne with great variety of substituents. However, they are materials with difficulty in processing to thin films. Diacetylenes usually do not give single crystals large enough for application, except very few examples and if they did quite often they do not undergo topochemical polymerization. The LangmuirBlodget technique is not so easy to obtain films thick enough for application and other techniques such as vapor phase deposition of diacetylene crystals or crystallization from the melt under pressure ${ }^{1}$ are interesting but limited to a few particular diacetylenes. The nonlinear optical properties of polydiacetylene single crystals may be superior to those of amorphous polydiacetylenes and diacetylene-containing polymers, but the latter have a significant advantage that their processing into thin films is simple, and therefore, the current interest is how to improve the optical quality of such films. Some of the films prepared from diacetylene-containing polymers have been proven to posses $\chi^{(3)}$ values of $10^{-9}-10^{-10}$ esu. ${ }^{2,3}$

There are a few studies on polymers which contain diacetylene groups in the main chains. Wegner ${ }^{4}$ reported early in 1970 synthesis of polyesters and polyurethanes consisting of hexa-1,3-diyne units, and they were photosensitive. However, they had low molecular weight and were useless for future study. Keul, et al. ${ }^{5}$ also reported polyesters and polycarbonates containing aliphatic diacetylene units, but no interesting properties of those polymers were found. Rubner ${ }^{6}$ reported qualitative studies on visible absorption spectra of polyurethanes containing 5,7-dodecadiyne units, which underwent cross-polymerization thermally or on

\footnotetext{
* To whom correspondence should be addressed.
} 
$\gamma$-irradiation. He used poly(tetramethylene oxide), hexamethylene diisocianate and 5,7dodecadiyne-1,12-diol for his polyurethanes. In such systems, the concentrations of diacetylene groups are extremely low and no interesting optical properties will be found.

The present authors previously prepared polymers containing aromatic diacetylene groups. They include polyesters which contain butadiynylene dibenzyl groups ${ }^{7}$ and a series of new diacetylene-containing high molecular weight polyamides which consist of $m, m^{\prime}$ butadiynylene dianilide units. $^{8}$ These polyamides have $\eta_{\text {inh }}$ greater than $1.0 \mathrm{dlg}^{-1}$ and can be cast into thin films which turn bluish-purple on UV-irradiation. It was also found previously ${ }^{9}$ that the polyesters prepared from 3-butyn-1-ol and diacid chlorides were photosensitive but the polymers had low molecular weights. By studying polymerization conditions, it was found that diacetylenecontaining polyesters having extremely high molecular weight can be obtained by oxidative coupling reaction. These polymers had low melting points and could be drown to extraordinarily strong fibers and films at room temperature. The synthesis and characterization of these polyesters are reported in this paper.

\section{EXPERIMENTAL}

\section{Materials}

1,2-Dichlorobenzene (ODCB) was distilled in vacuum. $N, N, N^{\prime}, N^{\prime}$-tetramethylenediamine (TMDA) was distilled before use. Other reagents were used as received (Aldrich).

\section{Monomer Synthesis}

The monomers, di(butyn-3-yl) succinate (1), di(butyn-3-yl) adipate (2), and di(butyn-3-yl) sebacate (3) were prepared by esterefication of 3-butyn-1-ol with succinyl chloride, adipoyl chloride and sebacoyl chloride respectively.

\section{Di(butyn-3-yl) Succinate (1)}

3-Butyn-1-ol $(10 \mathrm{mmol})$ was dissolved in $40 \mathrm{ml}$ pyridine and succinyl chloride $(4.8 \mathrm{mmol})$ was added dropwise with vigorous stirring at $0-5^{\circ} \mathrm{C}$. After $2 \mathrm{~h}$ stirring at room temperature the reaction mixture was poured into diluted cold sulfuric acid. The product was extracted with benzene and purified by column chromatography on silica gel with benzene followed by recrystallization from hexane. $T_{\mathrm{m}}=36^{\circ} \mathrm{C}$, yield $67 \%$. IR $\left(\mathrm{cm}^{-1}\right): 3280(\mathrm{CC}-\mathrm{H}), 2120$ $(\mathrm{C} \equiv \mathrm{CH})$, and $1740(\mathrm{C}=\mathrm{O})$.

\section{Di(butyn-3-yl) Adipate (2)}

Compound (2) was prepared similarly to (1). The reaction mixture was poured into diluted cold sulfuric acid, the product precipitated was filtered off and recrystallized from hexane 3 times. $T_{\mathrm{m}}=42^{\circ} \mathrm{C}$, yield $78 \%$. IR $\left(\mathrm{cm}^{-1}\right): 3280$ $(\mathrm{CC}-\mathrm{H}), 2120(\mathrm{C} \equiv \mathrm{CH})$, and $1740(\mathrm{C} \equiv \mathrm{O})$.

Di(butyn-3-yl) Sebacate (3)

Compound (3) was prepared similarly to (2). $T_{\mathrm{m}}=62^{\circ} \mathrm{C}$, yield $71 \%$. IR $\left(\mathrm{cm}^{-1}\right): 3280$ $(\mathrm{CC}-\mathrm{H}), 2120(\mathrm{C} \equiv \mathrm{CH})$, and $1740(\mathrm{C}=\mathrm{O})$.

\section{Polymer Synthesis}

Polymers were prepared by oxidative polycoupling of monomers $1-3$ in the presence of $\mathrm{CuCl}-\mathrm{TMDA}$ complex in ODCB.

Poly(octa-3,5-diynelene succinate) (4)

$2 \mathrm{~g}$ of di(butyn-3-yl) succinate (1), $0.09 \mathrm{~g}$ of $\mathrm{CuCl}, 1.8 \mathrm{ml}$ of TMDA, and $15 \mathrm{ml}$ of ODCB were heated to $75^{\circ} \mathrm{C}$. Oxygen was bubbled through reaction mixture with stirring for $1 \mathrm{~h}$. The green viscous solution was poured into n-propanol acidified with $\mathrm{HCl}$ and stirred for $5 \mathrm{~h}$. The fibrous precipitate was filtered off, washed with water and $n$-propanol and dried in vacuum at room temperature. Yield was $97 \%, \eta_{\text {inh }}$ in 1,1,2,2-tetrachloroethane (TCE) at $25^{\circ} \mathrm{C}$ was $0.91 \mathrm{dl} \mathrm{g}^{-1}$. IR $\left(\mathrm{cm}^{-1}\right) 2260,2200$, $2150(\mathrm{C} \equiv \mathrm{C}-\mathrm{C} \equiv \mathrm{C}), 1740(\mathrm{C}=\mathrm{O})$.

\section{Poly(octa-3,5-diynelene adipate) (5)}

Compound (5) was prepared similarly to (4) using $2 \mathrm{~g}$ of di(butyn-3-yl) adipate (2), $0.06 \mathrm{~g}$ of $\mathrm{CuCl}$, and $1.1 \mathrm{ml}$ of TMDA. The reaction was carried out for $45 \mathrm{~min}$. Yield was $99 \%, \eta_{\mathrm{inh}}$ 
in (TCE) at $25^{\circ} \mathrm{C}$ was $1.12 \mathrm{dlg}^{-1}$. IR $\left(\mathrm{cm}^{-1}\right)$ 2260, 2200, $2150(\mathrm{C} \equiv \mathrm{C}-\mathrm{C} \equiv \mathrm{C})$, and 1740 $(\mathrm{C}=\mathrm{O})$.

\section{Poly(octa-3,5-diynelene sebacate) (6)}

Compound (6) was prepared similarly to (5) using $2 \mathrm{~g}$ of di(butyn-3-yl) sebacate (3), $0.05 \mathrm{~g}$ of $\mathrm{CuCl}$, and $0.8 \mathrm{ml}$ of TMDA. Yield was $99 \%$, $\eta_{\text {inh }}$ in (TCE) at $25^{\circ} \mathrm{C}$ was $1.26 \mathrm{dlg}^{-1}$. IR $\left(\mathrm{cm}^{-1}\right) 2260,2200,2150(\mathrm{C} \equiv \mathrm{C}-\mathrm{C} \equiv \mathrm{C})$, and $1740(\mathrm{C}=\mathrm{O})$.

Elemental analysis data of monomers and polymers are listed in Table I. Monomer and polymer synthesis are shown in Scheme 1.

Cross-polymerization

Thermally induced cross-polymerization in the solid state and melt was carried out at 90 and $180^{\circ} \mathrm{C}$, respectively under nitrogen. Irradiation-induced cross-polymerization was carried out with $500 \mathrm{~W}$ medium pressure mercury

Table I. Elemental analysis data for monomers 1-3 and polymers 4-6

\begin{tabular}{|c|c|c|c|c|c|}
\hline \multirow{2}{*}{ Compound } & \multirow{2}{*}{ Formula } & \multicolumn{2}{|c|}{$\begin{array}{l}\text { Calculated } \\
\text { in } \%\end{array}$} & \multicolumn{2}{|c|}{ Found in $\%$} \\
\hline & & $\mathrm{C}$ & $\mathbf{H}$ & $\mathrm{C}$ & $\mathrm{H}$ \\
\hline $\mathbf{1}$ & $\mathrm{C}_{12} \mathrm{H}_{14} \mathrm{O}_{4}$ & 64.85 & 6.35 & 64.49 & 6.33 \\
\hline 2 & $\mathrm{C}_{14} \mathrm{H}_{18} \mathrm{O}_{4}$ & 67.18 & 7.25 & 67.23 & 7.21 \\
\hline 3 & $\mathrm{C}_{18} \mathrm{H}_{26} \mathrm{O}_{4}$ & 70.56 & 8.55 & 70.32 & 8.55 \\
\hline 4 & $\left(\mathrm{C}_{12} \mathrm{H}_{12} \mathrm{O}_{4}\right)_{n}$ & 65.45 & 5.49 & 64.98 & 5.51 \\
\hline 5 & $\left(\mathrm{C}_{14} \mathrm{H}_{16} \mathrm{O}_{4}\right)_{n}$ & 67.72 & 6.50 & 67.32 & 6.28 \\
\hline 6 & $\left(\mathrm{C}_{18} \mathrm{H}_{24} \mathrm{O}_{4}\right)_{n}$ & 71.02 & 7.95 & 70.83 & 7.71 \\
\hline
\end{tabular}

Monomer synthesis

$$
\begin{aligned}
& \mathrm{HC} \equiv \mathrm{C}\left(\mathrm{CH}_{2}\right)_{2} \mathrm{OH}+\mathrm{ClOCRCOCl} \stackrel{\mathrm{Py}}{\longrightarrow} \\
& \mathrm{HC} \equiv \mathrm{C}\left(\mathrm{CH}_{2}\right)_{2} \mathrm{OOCRCOO}\left(\mathrm{CH}_{2}\right)_{2} \mathrm{C} \equiv \mathrm{CH} \\
& \text { 1: } \mathrm{R}=-\left(\mathrm{CH}_{2}\right)_{2}- \\
& \text { 2: } \mathrm{R}=-\left(\mathrm{CH}_{2}\right)_{4}- \\
& \text { 3: } \mathrm{R}=-\left(\mathrm{CH}_{2}\right)_{8}- \\
& \text { Polymer synthesis } \\
& \text { 1, 2, or } 3 \stackrel{\mathrm{CuCl}, \text { TMDA, ODCB }}{\mathrm{O}_{2}} \\
& -\left(\mathrm{C} \equiv \mathrm{C}\left(\mathrm{CH}_{2}\right)_{2} \mathrm{OOCRCOO}\left(\mathrm{CH}_{2}\right)_{2} \mathrm{C} \equiv \mathrm{C}\right)_{n}{ }^{-} \\
& \text {Scheme } 1 .
\end{aligned}
$$

lamp.

\section{Measurements}

DSC and TGA were performed at a heating rate of $20^{\circ} \mathrm{C} \mathrm{min}^{-1}$ under nitrogen flow with a du Pont 2100. IR-spectra were taken using a Nikolet 510 p FT-IR spectrometer. UV-Spectra were taken using a UV-260 Shimadzu. X-Ray diffractometry was performed using a Siemens D-500 diffractometer with $\mathrm{Cu}-K_{\alpha}$ radiation of $1.540 \mathrm{~A}$. Polymer films used for UV measurements were prepared as follows: the polymers were dissolved in $\mathrm{CHCl}_{3}$ and the solutions were spread onto glass or quartz slides and left at room temperature for $2 \mathrm{~h}$ at atmosphere pressure to give semitransparent flexible films after removing the support.

\section{RESULTS AND DISCUSSION}

Polymers $4-6$ were white fibrous materials. They were soluble at room temperature in chlorinated aliphatic solvents such as TCE, chloroform and methylene chloride and strong films could be cast either from solutions or the

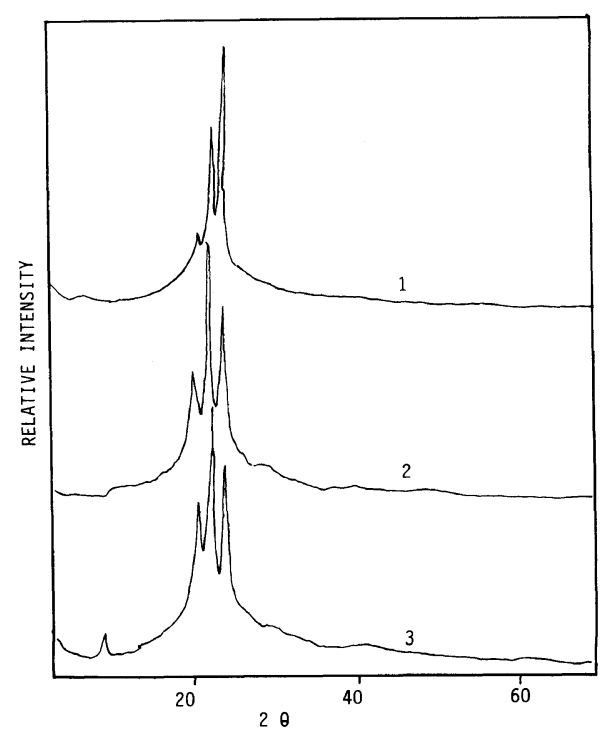

Figure 1. X-Ray diffraction patterns of polymer 4 (1), 5 (2), and 6 (3) after melting and cooling to room temperature. 
melts. The polymers were also soluble in hot aromatic hydrocarbons, ODCB, chlorobenzene and in glacial acetic acid, but slowly precipitated from the solutions when cooled to room temperature.

All polymers were highly crystalline as can be seen from the X-ray patterns in Figure 1.

\section{Thermal Properties}

DSC curves of the polymers $4-6$ are shown in Figure 2. All the polymers had endotherms in the region of $100-140^{\circ} \mathrm{C}$, attributed to melting. Polymers 4 and 5 had small endotherms at 110 and $123^{\circ} \mathrm{C}$, respectively, before the main endotherms. No melting was observed in these regions so we could ascribe the endotherms to solidstate transitions seen often in diacetylenes. ${ }^{10}$ All the polymers had exotherms which started above $200^{\circ} \mathrm{C}$ due to cross-linking of diacetylene groups in liquid state accompanying by partial decomposition at temperature above $280^{\circ} \mathrm{C}$. In TGA analysis of the polymers, weight loss started at $280^{\circ} \mathrm{C}$ and attained $35 \%$ at $400^{\circ} \mathrm{C}$. In the range of $130-180^{\circ} \mathrm{C}$, the polymer melts were stable enough to process the polymers into strong fibers and films.

\section{$U V$-Induced Cross-Polymerization}

All the polymers were photo sensitive and turned red on UV-irradiation, showing featureless absorption maximum in visible region

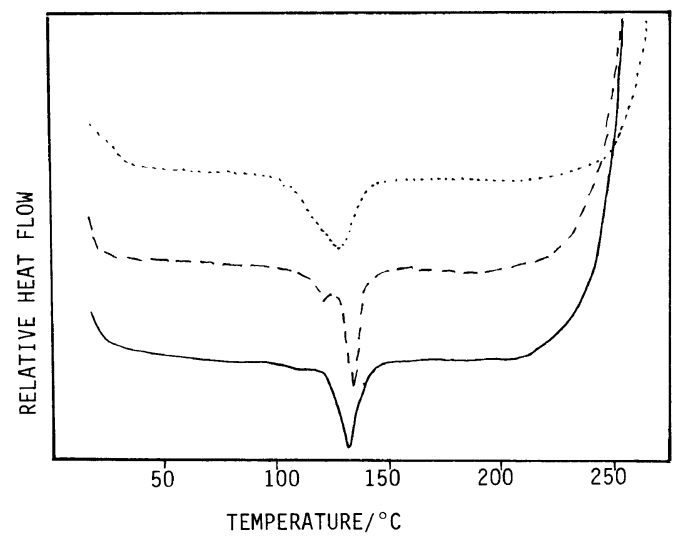

Figure 2. DSC curves of polymers $4(-), 5(--)$, and 6 $(\cdots)$ after melting and cooling to room temperature. indicating the polydiacetylene network formation shown in Scheme 2. Such topochemical cross-polymerization is known for some polymers $[4,5,6,8]$ but not all diacetylenecontaining polymers undergo this reaction. ${ }^{7}$ UV-Visible spectra of irradiated polymers are shown in Figure 3.

\section{Thermally Induced Cross-Polymerization}

Owing to the presence of diacetylene groups, the polymers can be cross-polymerized topochemically in the solid state on irradiation or thermally.

Thermally induced cross-polymerization in

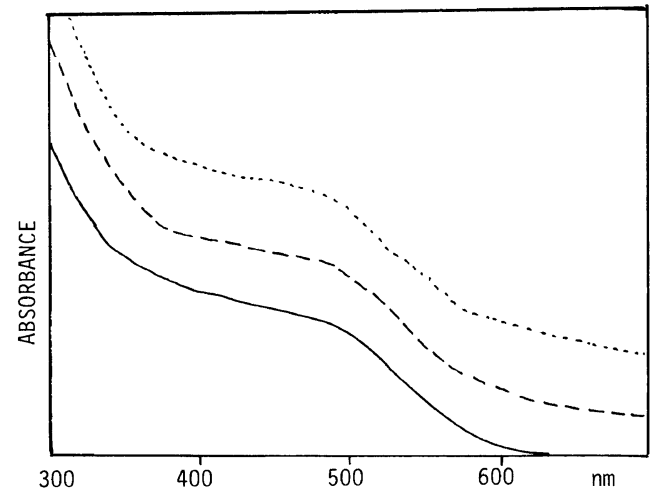

Figure 3. UV-Visible spectra of polymers $4(-), 5(--)$, and $6(\cdots)$, irradiated with a medium pressure mercury lamp for $30 \mathrm{~min}$.

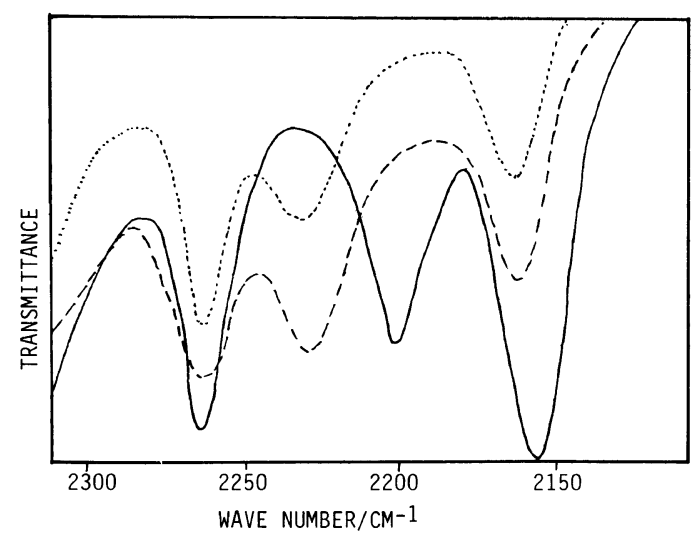

Figure 4. IR-Spectra of polymer 6 before $(-)$, after (--) thermal cross-polymerization in the solid state at $90^{\circ} \mathrm{C}$ for $96 \mathrm{~h}$ and irradiated with medium pressure mercury lamp for $30 \mathrm{~min}(\cdots)$. 


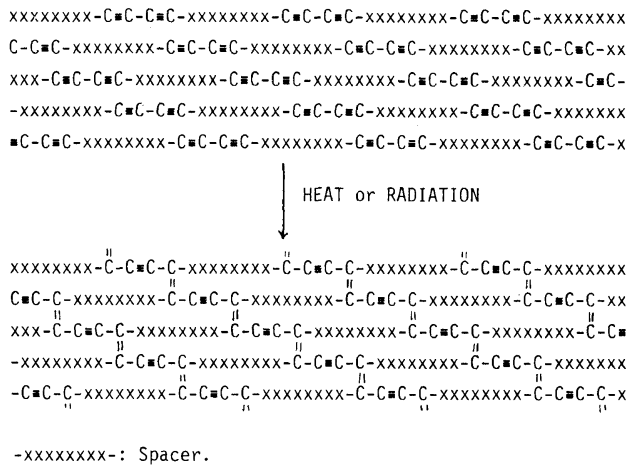

Scheme 2.

the solid state proceeded relatively slowly. It took several days at $90^{\circ} \mathrm{C}$ to attain detectable conversion of diacetylene groups as followed by IR-spectra of topochemically thermally cross-polymerizeded polymers. An example is shown in Fig. 4. Absorption bands characteristic of diacetylene groups at 2260, 2200, and $2150 \mathrm{~cm}^{-1}$ gradually decreased in intensity while new absorption band appeared at $2230 \mathrm{~cm}^{-1}$ associated with a conjugated triple bond of the polydiacetylene structure formed (Scheme 2). At the same time the polymers turned orange on heating and showed an absorption band in the visible region characteristic of polydiacetylene structure formation. All the thermally cross-polymerized polymers had broad absorption in the visible region similar to UV-cross-linked ones indicating of incompletely formed conjugated polydiacetylene network formed.

Thermal cross-linking of polymers $4-6$ in the molten state was also studied. When heated at $180^{\circ} \mathrm{C}$ under a nitrogen atmosphere, the molten polymer solidified within several hours and became dark-brown. IR-spectra of polymer 6 before and after heating for $4 \mathrm{~h}$ at $180^{\circ} \mathrm{C}$ is shown in Figure 5. Polymers $\mathbf{4}$ and $\mathbf{5}$ had spectra similar to that of 6 . As can be seen from the comparison in Figures 4 and 5, the spectra of solid-state cross-polymerized polymers and those cross-linked in the melt are identical. Absorption bands corresponding to

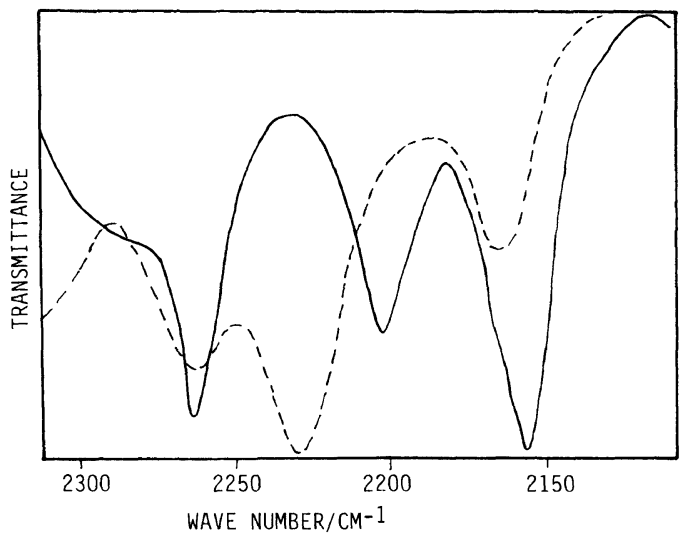

Figure 5. IR-Spectra of polymer 6 before (-), after (--) heating at $180^{\circ} \mathrm{C}$ for $4 \mathrm{~h}$.

diacetylene groups at 2260, 2200, and 2150 $\mathrm{cm}^{-1}$ decreased in intensity while new absorption band appeared at $2230 \mathrm{~cm}^{-1}$ associated with a conjugated triple bond of polydiacetylene structure (Scheme 2). Consequently, we may conclude that thermal cross-linking of the polymers $4-6$ in the melt and in the solid-state leads to a similar structure of cross-links. However, because of the nontopochemical character of cross-polymerization in the molten state, a less ordered structure will be formed as can be judged from the absence of long-length wave absorption maximum in the visible region. A recent work has shown that the 1,4-polymerization of diacetylene does not always occur exclusively within crystalline organization. ${ }^{11}$

An irreversible thermochromic transition was observed for both partially UV- and thermally cross-polymerized polymers $4-6$ in the solid state. This occurred for all the polymers on heating in the range of 110 $120^{\circ} \mathrm{C}$, accompanied by color changes from orange to light-yellow. An example of spectral changes is shown in Figure 6. The existence of a wide variety of thermochromic transitions in polydiacetylenes has been well documented on the molecular level. ${ }^{12}$ In this case the disappearance of the long wave absorption maximum can be explained by conformational 


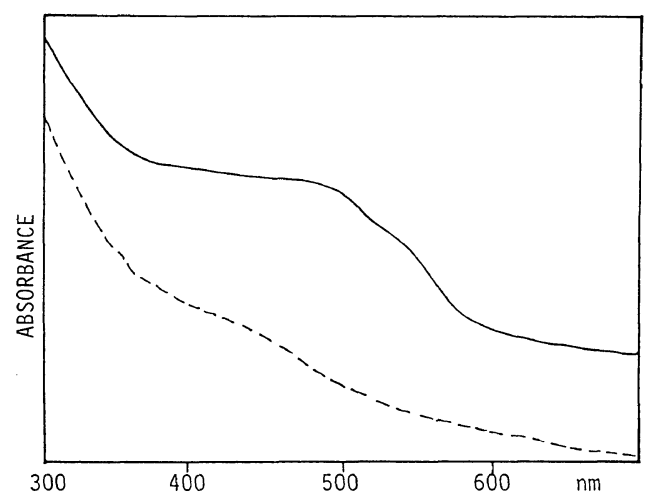

Figure 6. UV-Visible spectra of polymer 6 irradiated with a medium pressure mercury lamp for $30 \mathrm{~min}$ before $(-)$, and after heating at $115^{\circ} \mathrm{C}$ for $2 \min (--)$.

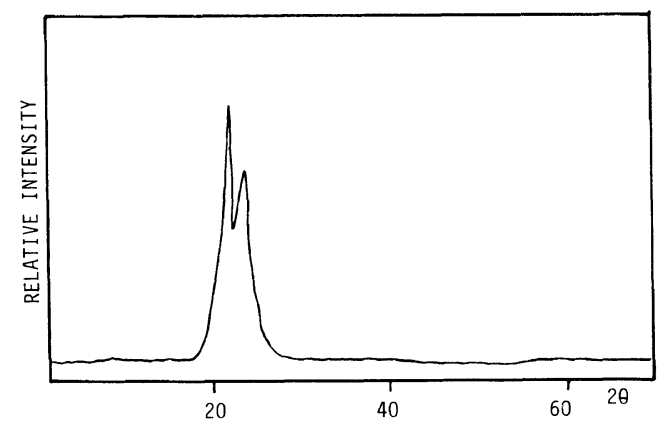

Figure 7. X-Ray diffraction pattern of the oriented part of polymer 6 film (elongation 150\%).

changes of the polymer chains which occur on heating when macromolecules start moving. Movement of polymer chains disrupts conjugation in the polydiacetylene network that bringing about the blue-shift of the absorption maximum.

All the polymers prepared could be stretched at room temperature up to $400 \%$. When stretched, the translucent crystalline films turned transparent. As can be seen from Figure 7, the cold-stretched samples are highly crystalline. According to optical polarizing microscopy data, these samples are optically anisotropic, which implies one-directional crystallites orientation.
In conclusion, we synthesized a series of new high molecular weight diacetylene-containing thermoplastic polyesters by the oxidative polycoupling of aliphatic diacids 3-butynyl diesters. The polyesters were highly crystalline and photosensitive. These and the results of previous work $^{8}$ show that the oxidative coupling reaction of terminal bisacetylenes can be successfully applied for preparation of different types of high molecular weight diacetylene containing polymers, provided that polymerization condition are siutable.

Acknowledgements. This work was supported financially by Grant IN 101793 provided by the Direction General de Asuntos de Personal Academico (DGAPA) of our University. Thanks are also due to Carmen Vazquez and L. Baños for assistance in the thermal analysis and X-ray diffractometry, respectively.

\section{REFERENCES}

1. H. Nakanishi, H. Matsuda, S. Okada, and M. Kato, Polymers for Advanced Technologies, 1, 75, (1990).

2. Luping Yu, Mai Chen, and L. Dalton, J. Polym. Sci., Polym. Chem. Ed., A, 29, 127 (1991).

3. T. Ogawa, "POLYMEX-93," Prepr., International Symposium on Polymers, Cancun, Mexico, November 1993, p 71 .

4. G. Wegner, Makromol. Chem., 134, 219 (1970).

5. S. Kuhling, H. Keul, and H. Hocker, Macromolecules, 23, 4192 (1990).

6. M. Rubner, Macromolecules, 19, 2129 (1986).

7. M. Estrada, G. Burillo, and T. Ogawa. Polymers for Advanced Technologies, 3, 419 (1992).

8. S. Fomine, T. Ogawa, Polym. J., 26, 95 (1994).

9. R. Neyra, C. Chavarin, and T. Ogawa, Abstracts, "Memorias de Division de Polimeros," 28th Congreso mexicana de Quimica Puro y Aplicada, Purto Vallarta, November 1992, p 60.

10. J. Kaiser, G. Wegner, and E. Fisher, Isr. J. Chem., 10, 157 (1972).

11. M. A. Schen, K. Kotowski, and J. Cline, Polymer, 32, 1821 (1991).

12. R. Chance, G. Patel, and J. Witt, J. Chem. Phys., 71, 206 (1979). 